\title{
LA REVOLUCIÓN MEXICANA Y SU REPERCUSIÓN EN AMÉRICA LATINA
}

\author{
Adalberto Santana*
}

RESUMEN: En este artículo se presenta una caracterización de la llamada Revolución Mexicana como un fenómeno político de amplias repercusiones en los países latinoamericanos durante buena parte del siglo xx. Revolución que, al igual que todo proceso transformador, mostró una sustancial modificación de las estructuras sociales y políticas del México de inicios del siglo XX, pero que, a su vez, tuvo sus propias características y elementos en común con otros procesos revolucionarios. De igual manera dicha revolución fue producto de condiciones objetivas y subjetivas en el marco de un desarrollo de las contradicciones nacionales e internacionales. De tal forma que la llamada Revolución Mexicana fue un hecho político excepcional, como lo es toda revolución, la cual tuvo una impronta en diversos órdenes: políticos, sociales y culturales en países y actores latinoamericanos.

Palabras Clave: Revolución Mexicana, Soberanía, Nacionalismo-revolucionario.

ABSTRACT: This article presents a particular characterization of the so-called "Mexican Revolution" as a political phenomena of wide repercussions in the Latin-American countries during a large period of the $x x$ century. This revolution, as any other transforming process, showed in general a substantial modification of the social and political structures of the Mexico of the beginnings of the Xx century, but which had its own characteristics and elements in common with other revolutionary processes. In the same way, such revolution was the product of objective and subjective conditions in the frame of the development of national and international contradictions. In such a way that the so-called mexican revolution was an exceptional political fact, as is any revolution, which cast a stereotype in diverse orders: political, social and cultural of other Latin-American countries and actors.

KEY WORDS: Mexican Revolution, Sovereignty, Revolutionary-nacioalism.

\footnotetext{
*Centro Coordinador y Difusor de Estudios Latinoamericanos, unAM (asantana@servidor.unam.mx).
} 


\section{INTRODUCCIÓN}

Sin duda hay muchas visiones e interpretaciones sobre la Revolución Mexicana*. Sin embargo, desde una interpretación más objetiva se parte del criterio de que esa revolución, lejos de ser la única, "estuvo lejos de ser una revolución social; más bien constituía una forma, inédita en la historia, de revolución política, a saber: una revolución populista. El modo en que nació y los fines que se propuso no parecen desmentirlo". ${ }^{1}$ En otra concepción que retoma el sentido y el examen que Jesús Silva Herzog hizo en un crítico ensayo, sostenía: “Ahora, después del tiempo transcurrido, pienso con cierta tristeza y siento con claridad que la Revolución Mexicana ya no existe; dejó de ser, murió calladamente sin que nadie lo advierta; sin que nadie, o casi nadie lo advierta todavía". ${ }^{2}$ En esa línea de pensamiento y considerando la caracterización de lo que fue la Revolución Mexicana, se afirma:

Vista desde esta perspectiva, la Revolución Mexicana (1910-1940), a pesar de sus limitaciones, fue un movimiento telúrico que transformó profundamente las estructuras económico-sociales, y sentó las bases para una nueva etapa del desarrollo ascendente del país y para el avance de las relaciones capitalistas, reafirmando la soberanía nacional. Por el carácter de las fuerzas que la promovieron y las reivindicaciones que la inspiraban, la Revolución Mexicana podemos considerarla como una revolución social, democrática, agraria y antiimperilista, que contribuyó decisivamente al fortalecimiento de

* En el presente texto empleo el concepto Revolución Mexicana como nombre propio con la implicación política del término utilizado por los estudiosos clásicos del tema que no adjetivizaron el nombre. De ahi que siguiendo esa tradición, prefiero el uso de las mayúsculas para designar ese trascendental hecho histórico y político del siglo XX.

${ }^{1}$ Arnaldo Córdova, La formación del poder político en México, México, Era, 1978 (Serie Popular Era, 15), p. 32.

2 Jesús Silva Herzog, "La Revolución Mexicana es ya un hecho histórico", Cuadernos Americanos, año XLIII, vol. CCLIII, marzo-abril, México, 1984, p. 7. También véase: ¿Ha muerto la Revolución Mexicana?, prep. y pról. de Stanley R. Ross, México, Sepsetentas, 1972. 
la conciencia y las tradiciones revolucionarias en el pueblo mexicano y de toda América Latina. ${ }^{3}$

En ese sentido, y con las anteriores caracterizaciones, ${ }^{4}$ identificamos a la Revolución Mexicana como el primer gran movimiento insurreccional de masas del siglo xx, que generó un modelo de elementos políticos y culturales, que tuvo un determinado impacto en los países latinoamericanos. Esto es, partimos de la consideración de que esta revolución es un hecho histórico-político que llegó a repercutir ampliamente en diversos campos de los países y hombres de nuestra América por su carácter popular y antiimperialista.

\section{La Revolución MeXicAna en LatinOAMÉRICA (1910-1940)}

A mediados del mes de septiembre de 1910 la dictadura del general Porfirio Díaz celebraba las fiestas del centenario de la Independencia nacional. Faltaban casi dos meses para que estallara la insurrección popular

${ }^{3}$ Alejo Maldonado Gallardo, Sergio Guerra Vilaboy y Roberto González Arana, Revoluciones latinoamericanas del siglo XX. Síntesis histórica y análisis historiográfico, Morelia, Universidad Michoacana de San Nicolás de Hidalgo, 2006, p. 144.

${ }^{4}$ Pero también hay diversas y muy destacadas obras en la historiografía del tema, cabe mencionar entre otras: Lázaro Cárdenas, Obras. Apuntes 1913/1940, tomo I, México, UNAM, 1972; James D. Cockcroft, Precursores intelectuales de la Revolución Mexicana (1910-1913), México, Secretaría de Educación Pública, 1985; Arnaldo Córdova, La ideología de le Revolución Mexicana. La formación del nuevo régimen, México, Era, 1973; Plutarco Elías Calles, Pensamiento político y social. Antología (1913-1936), pról., selec. y notas de Carlos Macías, México, FCE, 1992; Ricardo Flores Magón, Regeneración, 1900-1918. La corriente más radical de la Revolución Mexicana de 1910 a través de su periódico, pról., selec. y notas de Armando Bartra, México, Era, 1991; Adolfo Gilly, La Revolución interrumpida, 1910-1920: una guerra campesina por la tierra y el poder, México, El Caballito, 1971; Octavio Ianni, El Estado capitalista en la época de Cárdenas, México, Era, 1977; Álvaro Matute, Historia de la Revolución Mexicana 1917-1924. La carrera del caudillo, México, Colmex, 1988, vol. 8; Tzi Medin, Ideología y praxis política de Lázaro Cárdenas, México, Siglo XXI, 1973; Jesús Silva Herzog, Breve historia de la Revolución Mexicana, México, FCE, 1966; Leopoldo Zea, El Positivismo en México. Nacimiento, apogeo y decadencia, México, FCE, 1988. 
contra esa sangrienta dictadura. En esos momentos se estaba madurando una serie de condiciones objetivas y subjetivas para el inicio de un proceso insurreccional de masas contra el régimen imperante.

El 20 de noviembre comenzaría la primera revolución triunfante del siglo xx, conforme al llamado insurreccional del Plan de San Luis publicado por Francisco I. Madero. Ahí comenzó una cruenta lucha, que generó la pérdida de más de un millón de personas, cuando México tenía un poco más de 14 millones de habitantes. En ese proceso la formación social mexicana presenció primero la caída del régimen porfirista, lo que posibilitó que Madero llegara a la presidencia en 1911, después el 22 de febrero de 1913 el asesinato de Madero junto con el vicepresidente José María Pino Suárez, con lo que se origina un golpe de Estado en el que intervino el embajador estadounidense Henry Lane Wilson que prolongó el antiguo régimen de una dictadura militar ahora encabezada por Victoriano Huerta.

Esta situación generó una gran resistencia de todos los bloques opositores y revolucionarios contra el nuevo gobierno militar. ${ }^{5}$ Tras la derrota de Huerta en julio de 1914, Venustiano Carranza, apoyado en el Plan de Guadalupe, llegó a la presidencia de México. Durante su mandato se realizó, el 10 de octubre de ese año, en la ciudad de Aguascalientes, uno de los episodios más destacados de la historia de la Revolución Mexicana: la Convención Revolucionaria de Aguascalientes, la cual, dominada por las fuerzas villistas y zapatistas, nombraron a Eulalio Gutiérrez como presidente interino el 6 de noviembre de 1914, y designaron, el 16 de enero de 1915, a Roque González Garza como el nuevo mandatario convencionista y el 11 de junio de 1915 a Francisco Lagos Cházaro. Esto mostraba el enfrentamiento entre los dos principales bloques políticos: carrancistas y vi1listas-zapatistas. Finalmente la Convención fue disuelta y tras convocar Carranza al Congreso constituyente el 5 de febrero de 1917, en la ciudad de Querétaro, se promulga la nueva Constitución mexicana.

\footnotetext{
${ }^{5}$ Véase un texto que brinda una fresca lectura de aquellos momentos: John Reed, México insurgente, Buenos Aires, Centro Editor de América Latina, 1971.
} 
Entre 1918 y 1919, al sur del territorio mexicano, Emiliano Zapata y sus destacamentos guerrilleros seguían resistiendo a las fuerzas carrancistas. Pero el cerco se fue estrechando hasta que el 19 de abril de 1919 Zapata fue asesinado. Las fuerzas que encabezaba Venustiano Carranza se hicieron entonces hegemónicas, pero también comenzó la lucha interna por el poder. El grupo asentado en Sonora, que encabezaba el general Álvaro Obregón, proclamó el Plan de Agua Prieta. Carranza, acosado, emigró de la ciudad de México, pero en su huida fue traicionado y fusilado en ese año de 1920. Quedó como presidente provisional Adolfo de la Huerta, del $1^{\circ}$ de junio al $1^{\circ}$ de diciembre, quien, posteriormente, entregó la primera magistratura al general Álvaro Obregón, cerrándose así la fase armada de la Revolución Mexicana.

Para los inicios de los años veinte, México había vivido la inestabilidad política, producto del derrumbe del viejo régimen y del establecimiento del nuevo con un carácter revolucionario. Resultaba también con ello un problema para la visión que dominaba en Estados Unidos. Recordemos que en febrero de 1917 los distintos bloques de poder, emanados del proceso revolucionario, habían logrado establecer un pacto nacional al aprobar la primera constitución social del siglo XX. En esos años también se desarrolla la Primera Guerra Mundial en Europa y a finales de 1917 los bolcheviques tomaban el poder en Rusia. En ese convulsionado periodo de transición es cuando México restablece y amplía sus relaciones con diversos países del mundo, entre ellos la Unión Soviética.

Éstos eran también los tiempos en que las empresas bananeras y fruteras buscaban concesiones para explotar los recursos de las naciones latinoamericanas. México y otros países de la región padecían las presiones de las empresas estadounidense e inglesas, ${ }^{6}$ predominaba la

${ }^{6}$ Cfr. Centroamérica en crisis, México, Colmex, 1984. Al respecto también pueden consultarse los trabajos de Gregorio Selser, en particular: El pequeño ejército loco. Operación México-Nicaragua, texto que tiene diversas ediciones, entre ellas la publicada en Managua por Nueva Nicaragua en 1980, así como el de José Luis Ceceña, México en la órbita imperial, México, El Caballito, 1970. 
economía imperialista del enclave. Por lo tanto los recursos del subsuelo del país figuraban como un punto central que el nuevo Estado revolucionario mexicano requería recuperar.

Esto llevó a un fuerte enfrentamiento diplomático entre el gobierno de Álvaro Obregón y el estadounidense. Son los años entre 1920-1924 cuando en México la Revolución se consolida como proyecto político-social: se fortalece la lucha antiimperialista y emerge el nacionalismo-revolucionario. José Vasconcelos y otros intelectuales radicados en México le dan contenido ideológico a este proyecto.

Durante el gobierno obregonista comenzó la más importante campaña cultural vivida en México, la que inició José Vasconcelos, quien en 1920 fue rector de la Universidad Nacional y Secretario de Educación Pública entre 1921 y 1924. Durante la renovación educativa se le dio gran impulso a la cultura nacional y al latinoamericanismo. En el lema de la Universidad se recogía ese sentido: "Por mi raza hablará el espíritu" y en su escudo figuraban un águila y un cóndor teniendo al centro el mapa de América Latina. Era un momento cumbre del desarrollo cultural revolucionario. Fue la etapa en la que José Clemente Orozco, Diego Rivera y David Alfaro Siqueiros iniciaron su gran obra muralista junto con otros grandes exponentes de la escuela mexicana de pintura. ${ }^{7}$

Vasconcelos era precisamente uno de los más fervientes admiradores de la pintura muralista, y sus encargos en ese sentido eran numerosos, en su afán

\footnotetext{
${ }^{7}$ Diego Rivera pintó por encargo de Vasconcelos su primer mural en el Anfiteatro Simón Bolivar del edificio de la Escuela Nacional Preparatoria (ENP), centro de enseñanza donde Frida Kahlo conocería al pintor mexicano, sin que él todavía llegara a conocerla, cuestión que ocurrió en 1926 cuando sirvió de modelo para los murales de Palacio Nacional. Testimonio narrado al autor del presente ensayo por la profesora de danza folclórica mexicana Alura Flores, amiga y condiscípula en esos años de la famosa pintora mexicana, ambas integrantes de la generación 22-24 de la ENP, la cual contaba con dos mil alumnos y apenas tenía unas tres decenas de alumnas. Cabe también hacer notar que los pintores Diego Rivera, David Alfaro Siqueiros y Xavier Guerrero fundaron la Unión Independiente del Sindicato Revolucionario de Obreros Técnicos, Pintores y Escultores, a la vez que formaron parte en aquellos años del Comité Central del Partido Comunista Mexicano, fundado en 1919.
} 
por decorar los muros de los edificios públicos mexicanos con auténticas muestras de un arte autóctono y que fuese representativo del pueblo y del arte mexicanos. ${ }^{8}$

Éste es un periodo donde estudiantes, intelectuales y exiliados latinoamericanos en México se vinculan a la Revolución Mexicana. Por ejemplo, en octubre de 1923, el gobierno dirigido por el presidente Álvaro Obregón ordenó el cierre de su consulado en Caracas y retiró a los cónsules venezolanos en la ciudad de México y el puerto de Tampico, quienes eran representantes de la dictadura de Juan Vicente Gómez (1908-1935). En el comunicado oficial que daba a conocer la noticia se señalaba: "El Gobierno de México ha declarado que no tiene por esta causa ningún agravio con el pueblo venezolano, que continúa contando con la simpatía de México". 9

La ruptura de relaciones diplomáticas en gran medida estaba motivada por las diferencias político-ideológicas dominantes en cada uno de los países referidos. En México era hegemónico el proyecto revolucionario que cuestionaba con su práctica y discurso a la tiranía de Juan Vicente Gómez, la cual era muy semejante a la que había establecido en México el dictador Porfirio Díaz entre 1877 y 1910. La situación que generó en gran medida esa ruptura diplomática tenía como elementos y actores a los exiliados políticos venezolanos en México y a destacados intelectuales del México revolucionario como Diego Rivera, José Vasconcelos y Carlos Pellicer entre otros. Vasconcelos, entonces rector de la Universidad Nacional, en una arenga pronunciada el 12 de octubre de 1920 en el Anfiteatro Simón Bolívar de la Universidad, señalaba que en Venezuela gobernaba todavía "el último de los tiranos de la América española, el más monstruoso; el más repugnante y el más despreciable de

\footnotetext{
${ }^{8}$ Juan Gallardo Muñoz, Diego Rivera, Madrid, Dastin, S. L, 2003 (Grandes Mexicanos Ilustres), p. 77.

${ }^{9}$ Felícitas López Portillo T., Las relaciones México-Venezuela, 1910 - 1960: una perspectiva desde la diplomacia mexicana, Morelia, unAm/Universidad Michoacana de San Nicolás Hidalgo, 2005, p. 40.
} 
todos los déspotas que ha producido nuestra infortunada estirpe". ${ }^{10}$ Afirmaba a la vez: "No debemos callar el hecho de que Juan Vicente Gómez es un cerdo humano que deshonra nuestra raza y deshonra a la humanidad". ${ }^{11}$ De tal manera que el mismo Vasconcelos convocó a los estudiantes mexicanos y latinoamericanos a manifestarse por las calles de la ciudad de México contra el dictador de Venezuela. ${ }^{12}$

Toda esa presión política funcionó para lograr la liberación de los presos políticos venezolanos, algunos de los cuales llegaron al México revolucionario de los años veinte. Lo que creó, incluso, condiciones para organizar una expedición de exiliados venezolanos a costas de su país. ${ }^{13}$ De igual manera en esos años en México se lograron impulsar proyectos antiimperialistas como el de la Alianza Popular Revolucionaria Americana (APRA) de Raúl Haya de la Torre, organización que nace en la Universidad Nacional de México en 1924 como un proyecto de partido político latinoamericano. En ese mismo año, también, va a morir asesinado por los terratenientes y los rebeldes delahuertistas otro destacado revolucionario: Felipe Carrillo Puerto, fundador del Partido Socialista del Sureste, quien llegó a ser gobernador y uno de los principales caudillos revolucionarios en la península de Yucatán. ${ }^{14}$

${ }^{10}$ Ibid., 30.

${ }^{11}$ Loc. cit.

${ }^{12}$ Loc. cit.

${ }^{13}$ Otro acontecimiento semejante a esa expedición del vapor Superior, fue la organizada en 1931. En esa acción estuvieron involucrados varios ciudadanos mexicanos que fueron a prisiones de Juan Vicente Gómez. Entre distintos hechos históricos de la oposición venezolana radicada en México, Sosa de León anota que el Partido Revolucionario Venezolano (PRV) núcleo del Partido Comunista Venezolano (PCV), fue fundado en México el 6 de julio de 1926, por los venezolanos: Miguel Zúñiga Cisneros, Salvador de la Plaza, Gustavo Machado, Carlos León Bartolomé Ferrer, María León, Humberto Tejera y Félix Terán entre otros. Mireya Sosa de León, "La aventura del vapor mexicano Superior en las costas venezolanas: un episodio en las relaciones entre Venezuela y México", en Laura Muñoz [coord.], México y el Caribe, vínculos, intereses, región, México, Instituto Mora/AMEC/CONACYT, 2002, t. 2, pp. 127-162, p. 130.

${ }^{14}$ Véase Manuel Sarkisyanz, Felipe Carrillo Puerto. Actuación y muerte del apóstol rojo de los mayas, México, Cámara de Diputados LVIII Legislatura, 2003. 
Concluido el gobierno obregonista llegó a la presidencia de México el general Plutarco Elías Calles (1924-1928). Es un momento en que se fortalece en lo interno el llamado fenómeno político de la Revolución Mexicana y en lo externo adquiere compromisos de solidaridad con la autodeterminación nacional. Por ejemplo, en la región centroamericana el gobierno callista apoyaba al gobierno legítimo de los liberales en Nicaragua frente al apoyo que brindaba la Casa Blanca a los conservadores. En palabras del fundador del Partido Nacional Revolucionario (PNR) y presidente de México, tal cuestión la interpretaba así:

El gobierno de México ha diferido en este asunto del criterio de los Estados Unidos por razones de orden moral. Después de muchos años de existir en Nicaragua una tiranía personificada por la familia Chamorro y Adolfo Díaz, se estableció en aquel país un gobierno constitucional, nacido de una elección popular. Este gobierno estaba representado por el presidente Solórzano y por el vicepresidente Sacasa, estando los demás poderes constituidos legítimamente. Era un gobierno que tenía todas las características de legalidad. $\mathrm{Y}$ estaba desarrollando sus actividades en perfecta tranquilidad y haciendo esfuerzos por ver si conseguía el mejoramiento en las colectividades de su país. En estas condiciones, uno de los viejos dictadores de Nicaragua no podía quedar satisfecho con esa situación y se lanzó a la lucha, lucha que fue encabezada por el vicepresidente Sacasa, que representa la legalidad en Nicaragua. Se establecieron dos gobiernos: el gobierno de la violencia y el de la legalidad; México ha reconocido al gobierno de la legalidad. Ese es nuestro criterio respecto de la situación de Nicaragua. ${ }^{15}$

Esto significaba que el nuevo Estado comenzaba su primera modernización tanto en lo interno como en lo externo. Se institucionaliza el poder político que unifica a los distintos grupos emergidos del proceso revolucionario. Se forma con ello el PNR en 1929, como un órgano de gestión y disciplina política. Se hace una alianza estratégica con amplios sectores de la burguesía tradicional y en gran medida también se frena la reforma agraria y se favorece la corrupción sindical. En la infraes-

${ }^{15}$ Carlos Macías Richard, Plutarco Elías Calles: pensamiento politico y social. Antología (1913-1936), México, FCE, 1988, p. 158. 
tructura del país se avanza en la construcción de caminos y el sistema de riego, el funcionamiento del crédito por medio del Banco de México y del Crédito Agrícola y Ejidal. En el terreno político, es asesinado el general Álvaro Obregón el 17 de julio de 1928, después de haber triunfado en las elecciones presidenciales. Su asesinato es atribuido a sectores ultraderechistas ligados a la rebelión cristera. ${ }^{16}$ Con ese acontecimiento, se forma lo que se conoce como el "maximato" (1929-1934). Plutarco Elías Calles figura como "jefe máximo" y como presidentes formales quedan sucesivamente: Emilio Portes Gil, Pascual Ortiz Rubio y Abelardo L. Rodríguez. Al respecto Lorenzo Meyer nos dice:

La característica sobresaliente de este periodo fue la paulatina institucionalización de la participación de los nuevos actores — campesinos y obrerosbajo la dirección del Estado. El ejército continuó siendo la principal base del poder del gobierno revolucionario. De todas formas, se dieron entonces los primeros pasos para acabar con el caudillismo militar con medidas como la rotación de los jefes de las zonas militares. Las rebeliones militares de 1923 y 1929 — que dividieron al ejército-y otros alzamientos menores sirvieron para eliminar a algunos de los caudillos secundarios, uniformar al grupo gobernante y abatir un tanto a los poderes locales a favor del gobierno central. ${ }^{17}$

Estos también son años (1926-1929) en los cuales la Revolución Mexicana va a incidir ideológicamente en uno de los guerrilleros más destacados de la primera mitad del siglo xx latinoamericano: Augusto C. Sandino,

${ }^{16}$ La guerra cristera comenzó en 1926 contra el gobierno. Era un movimiento armado dirigido por el clero mexicano en contra de las políticas laicas y anticlericales del nuevo Estado revolucionario. El presidente Calles desterró a los sacerdotes extranjeros y al representante del Vaticano. A la par, los rebeldes levantaron las banderas agrarias del programa cristero, ligado a la tradición católica de las masas campesinas. El conflicto duró hasta 1929, en el gobierno de Emilio Portes Gil se negoció con la cúpula religiosa marcando un respeto del Estado mexicano por su estructura interna. El autor material del asesinato de Álvaro Obregón fue José León Toral. Una reconstrucción dramática del hecho lo narra Vicente Leñero en su obra: "El magnicidio (asesinato de Obregón)”, en Tres guiones cinematográficos, México, Marcha Editores, 1982, pp. 9-98.

${ }^{17}$ Lorenzo Meyer, "Cambio político y dependencia", en La política exterior de México: realidad y perspectivas, México, Colmex, 1972, p. 20. 
héroe nicaragüense que durante su primera estadía en México asimila diversas experiencias políticas revolucionarias. Al respecto escribiría Carlos Fonseca Amador, fundador del Frente Sandinista de Liberación Nacional:

En 1912 viajó fuera del país hacia otras tierras, al igual que miles de nicaragüenses. Conoció varios países centroamericanos, México y Estados Unidos, de este último retornó a México, donde aún se olía a pólvora de las balas disparadas por los oprimidos campesinos que encabezó el guerrillero Emiliano Zapata.[...] En México trabajó en Cerro Azul, Veracruz, como obrero mecánico de las instalaciones de la compañía petrolera norteamericana, Huasteca Petroleum Company. Despreciando el privilegio de su condición de obrero calificado, decidió regresar a la patria y ocupar un lugar en la lucha. ${ }^{18}$

Estas enseñanzas más tarde las pondría en práctica durante el desarrollo de la guerra contra la intervención estadounidense en Nicaragua entre 1926 y $1933 .{ }^{19}$ La tercera década del siglo xx fue un momento en el que Sandino y su Ejército Defensor de la Soberanía Nacional de Nicaragua luchaban contra la intervención estadounidense. El héroe de las Segovias contó pragmáticamente con el apoyo del gobierno mexicano y desinteresadamente con amplias capas de la población mexicana (intelectuales, artistas, estudiantes, políticos, etc.). Recordemos que Diego Rivera, Frida Kahlo y Julio Antonio Mella (exiliado cubano en México), habían participado activamente en el Comité Manos Fuera de Nicaragua. En la segunda visita de Sandino a tierras mexicanas permaneció desde junio de 1929 en Yucatán hasta abril de 1930. Al final de ese lapso se le permitió visitar la ciudad de México para entrevistarse con el presidente Emilio Portes Gil y el general Plutarco Elías Calles, asimismo realizó distintas actividades a favor de su lucha libertadora. ${ }^{20}$ Sobre esa visita Sandino señaló en una

${ }^{18}$ Carlos Fonseca Amador, "Sandino guerrillero proletario", en Bajo las banderas del sandinismo, Managua, Nueva Nicaragua, 1981, p. 263.

${ }^{19}$ Adalberto Santana, "Sandino en México", Coatepec. Revista de la Facultad de Humanidades de la UAEM, núm. 2, año 2, Toluca, UAEM, septiembre, 1988, pp. 66-68.

${ }^{20}$ Cfr. Sergio Ramírez Mercado, El pensamiento vivo de Sandino, Managua, Nueva Nicaragua, 1981, pp. IX-LXXXV; Edelberto Torres, Sandino, México, Katún, 1983, pp. 161-211 y Volker Wünderich, Sandino, Managua, Nueva Nicaragua, 1995. 
entrevista: "Debo además mencionar que todos mis gastos de viajes y permanencia en México me fueron reconocidos y fueron por cuenta del Gobierno de México. Conste, que sin solicitarlo ni empeñarnos en ningún compromiso político". ${ }^{21}$

Tras el retiro de las tropas estadounidenses de Nicaragua en 1933, llegó a ese país centroamericano una relativa calma que finaliza con el aniquilamiento de los principales dirigentes sandinistas. El 21 de febrero de 1934, al igual que Francisco I. Madero, Emiliano Zapata y Francisco Villa, el General de Hombres Libres es, junto con los generales Francisco Estrada y Juan Pablo Umanzor, miembros de su Estado Mayor, asesinado en el Campo Marte de Managua. ${ }^{22}$ Con ese plan del embajador estadounidense en alianza con el jefe director de la Guardia Nacional, el general Anastasio Somoza toma de facto el poder, consolidando una dinastía que proseguirá hasta el 19 de julio de 1979 cuando triunfa la Revolución Popular Sandinista. ${ }^{23}$

Durante este periodo, a principios de 1929, ocurre también en México otro dramático acontecimiento. Uno de los principales asilados políticos, Julio Antonio Mella, es asesinado por órdenes del dictador cubano Gerardo Machado Morales; cae asesinado por la espalda en las calles de la ciudad de México cuando iba acompañado de la fotógrafa Tina Modotti. ${ }^{24}$ Recordemos que Mella vivió exiliado en México, llegó al país en 1926 y se destacó como un dirigente estudiantil de la Universidad Nacional de México y también formó parte de la dirección política del Partido Comunista Mexicano (PCM), así como de distintas agrupa-

${ }^{21}$ José Román, Maldito país, s.1., Ediciones El Pez y La Serpiente, 1979, p. 105.

${ }^{22}$ Carlos Fonseca Amador, "Crónica secreta: Augusto César Sandino ante sus verdugos", en Bajo las banderas ..., pp. 281-298; Anastasio Somoza, El verdadero Sandino o el calvario de las Segovias, Managua, Tipografía Robelo, 1936 y Torres, op. cit., pp. 271-337.

${ }^{23}$ Cfr. Julio López C., et al., La caída del somocismo y la lucha sandinista en Nicaragua, San José (Costa Rica), EDuCA, 1979 y Oleg Ignatiev y Guénrij Borovik, La agonía de una dictadura, Moscú, Editorial Progreso, 1980.

${ }^{24}$ Mella había sido fundador, junto con Carlos Baliño en el año de 1925, del primer Partido Comunista Cubano, y llegó a ser uno de los principales dirigentes estudiantiles en Cuba y México donde proseguía sus estudios en la Universidad Nacional. 
ciones antiimperialistas. Dramáticamente Mella murió por órdenes de Machado el 10 de enero de 1929, el mismo año en que se logró la autonomía universitaria. ${ }^{25}$

Este periodo que narramos (1910 a 1934), es una fase en que las tropas estadounidenses llegan a ocupar el puerto de Veracruz en 1914, tal como lo harían en Haití desde ese año hasta 1934, República Dominicana en 1916, Nicaragua de 1912 a 1925 y de 1926 a 1933 y Cuba en 1906, 1912, 1917 y 1933. Panamá, que cumplió 100 años de vida independiente el 3 de noviembre de 2003, también debe su propia existencia al protectorado estadounidense que fue formado en 1903, tal como lo ha sido políticamente Puerto Rico hasta nuestros días. Ése era el escenario latinoamericano durante los primeros años del desarrollo de la lucha armada en México y de los primeros quince años de relativa calma.

En esta misma fase de los años treinta se comienzan a implantar algunas dictaduras en varios países latinoamericanos bajo la influencia de Estados Unidos, principalmente en el área del Caribe y Centroamérica, situación que en buena medida fue condicionada por la crisis de 1929, cuando las economías de los países latinoamericanos resintieron el cisma económico en sus exportaciones. A manera de ejemplo, en 1930 en República Dominicana comienza la dictadura de Rafael Leónidas Trujillo que culmina en 1961. En Chile renuncia el presidente Carlos Ibáñez. En 1932 comienza la Guerra del Chaco entre Bolivia y Paraguay que culminaría en 1936. Así también en ese año, en El Salvador se desata la insurrección que encabeza Agustín Farabundo Martí, la que finalmente es aplastada por la dictadura de Maximiliano Hernández Martínez. En Guatemala el arribo al poder de Jorge Ubico entre 1931 y 1944 significó una gran entrega de la soberanía a los capitales extranjeros como la United Fruit Company.

Esta situación en buena medida explicaba un hecho destacado en 1930, como fue el nacimiento de una de las manifestaciones políticas más brillantes de la diplomacia de la Revolución Mexicana: la llamada

${ }^{25}$ Cfr. Dais Cupull y Froylán González, Asi mi corazón. Apuntes biográficos sobre Julio Antonio Mella, La Habana, Casa Editorial Abril, 2004. 
Doctrina Estrada, postura diplomática que nació ese año cuando el secretario de Relaciones Exteriores, Genaro Estrada, hizo una declaración sobre algunos sucesos que estaban ocurriendo en los países latinoamericanos. En esa ocasión manifestó que México no se pronunciaría.

Finalmente el clímax de la Revolución Mexicana se vivió durante el régimen de Lázaro Cárdenas del Río, esto es, entre 1934 y 1940. Recordemos que en ese periodo histórico, el general Cárdenas logra resquebrajar la hegemonía del general Calles, pero también con ello logró representar a una pequeña burguesía nacionalista-revolucionaria, que comenzaba a recuperarse después de la crisis del 29. Para la política cardenista el Estado tenía que desempeñar un papel central en el nuevo rumbo de la nación, tanto en su ordenamiento político como en la transformación económica y, a su vez, en la generación de riquezas y en su distribución. En ello tenían un papel central los sectores de masas de los más amplios grupos populares de la nación. Así el ejido iba a desempeñar un papel capital en el impulso al desarrollo agrícola. En lo político Cárdenas frenó al callismo con el destierro del "jefe máximo" en 1936 y se vio apoyado en la alianza con los sectores obreros y campesinos, sobre todo cuando se crean la Confederación de Trabajadores de México (CTM) y la Confederación Nacional Campesina (CNC), lo que socialmente fortaleció al aparato estatal. La inflación creció pero a su vez dinamizó la economía al movilizar el aparato productivo. Con estas condiciones, en 1938 el presidente modificó la estructura del partido oficial tomando el nombre de Partido de la Revolución Mexicana (PRM) y estableció cuatro sectores fundamentales en la estructura partidaria: el obrero, el campesino, el militar y el popular.

Este partido fue un instrumento clave para uno de los objetivos esenciales de su gobierno revolucionario: la nacionalización del petróleo y la expropiación de los bienes de las empresas petroleras extranjeras el 18 de marzo de 1938. Esto motivó una fuerte presión por parte de Estados Unidos; se llegó finalmente a fijar una indemnización a las empresas afectadas. ${ }^{26}$ Así, durante esa nueva etapa, la Revolución Mexicana se puede resumir en el hecho de que:

${ }^{26}$ Cfr. La expropiación del petróleo 1936-1938, México, FCE, 1981. 
Cárdenas entregó a los campesinos 17.8 millones de hectáreas y puso fin al predominio de una economía agrícola basada en la hacienda. El gasto gubernamental en la construcción de obras de infraestructura y de beneficio social superó por primera vez los gastos puramente administrativos, surgiendo definitivamente un importante sector paraestatal - cuya influencia decisiva en la marcha de la economía perdura hasta el presente. ${ }^{27}$

Cabe apuntar que en el gobierno de Lázaro Cárdenas, se dieron importantes muestras de la plena independencia de la política exterior mexicana. Una de ellas fue el asilo a miles de refugiados españoles después de la derrota de la República Española, así como del asilo a destacados opositores políticos; uno de los más famosos sería León Trotsky.

\section{CRisis de LA ReVOlución MEXICANA y LATINOAMÉRICA (1940-2006)}

Con el gobierno del general Manuel Ávila Camacho (1940-1946), con un perfil mucho más moderado, en la década siguiente comenzaba a declinar la Revolución Mexicana. Al calor de la crisis de la Segunda Guerra Mundial, el gobierno mexicano todavía manifestaba una ideología nacionalista-revolucionaria que mantenía una política de rechazo al fascismo. Sin embargo, fue un periodo en el cual el área de Centroamérica y el Caribe se redimensionan para Estados Unidos como un zona clave en recursos y fuente de materias primas primordiales para el funcionamiento de su economía. Al final de este periodo gubernamental el PRM sufrió no sólo un cambio de nombre sino, también, de iniciativas; quedó como Partido Revolucionario Institucional (PRI), nominación que ha durado hasta nuestros días. Con esa transformación política partidaria, los sectores populares (obreros y campesinos) perdieron influencia y los sectores de las clases medias altas y de la burguesía industrial y agrícola lograban mayores beneficios. Entre ellos destacó el hecho de que "el partido fue, en definitiva, más un instrumento de apoyo y control del gobierno que un agregado y articulador de las demandas de sus miembros". ${ }^{28}$

${ }^{27}$ Meyer, op. cit., p. 25.

${ }^{28}$ Ibid., p. 28. 
En tanto que en otras regiones de América Latina donde la Revolución Mexicana tenía una influencia directa, como en el istmo centroamericano, se suscitó toda una serie de situaciones que resultaron de la inestabilidad política y económica por la que transitaba la mayoría de los países centroamericanos. Ahí, en los inicios de los años cuarenta, se fortalecía la estructura de poder de la oligarquía terrateniente y los monopolios bananeros. En tanto que en México el gobierno de Miguel Alemán Valdés (1946-1952), se constituyó en la primera administración de un civil y se caracterizó por abrir las puertas al capital extranjero y la modernización del país con la construcción de grandes obras públicas. Este gobierno le cedió la presidencia a Adolfo Ruiz Cortines (1952-1958) que, entre las mejores conquistas de su gobierno, logró la aprobación de la ley que otorgó el voto a las mujeres en 1953. Así, su gestión se caracterizó por ser una de las pocas administraciones posrevolucionarias con menos sobresaltos. Lo más destacado en ese periodo respecto a América Latina fue el respaldo otorgado a los refugiados guatemaltecos que llegaron al país tras el derrocamiento del gobierno del general Jacobo Arbenz Guzmán y el asilo mexicano a otros revolucionarios y opositores latinoamericanos.

Esto quiere decir que, a finales de los años cuarenta y durante la década de los cincuenta, se desarrolló en el Caribe y en el istmo centroamericano un periodo de inestabilidad agravado por las dictaduras y a la vez un surgimiento de nuevos movimientos revolucionarios que tendrían en México una plataforma necesaria para cobrar fuerzas e impulso. En el caso del escenario político de Nicaragua, Cuba, Venezuela, Colombia y República Dominicana se vivía un escenario donde predominaban dictaduras semejantes a la de Tiburcio Carías Andino en Honduras. Ahí, por ejemplo, se vivía el siguiente panorama:

En cárceles del país y el exilio había centenares de hondureños acusados de promover acciones subversivas contra el régimen cariísta. Gran cantidad de compatriotas, entre ellos el novelista Ramón Amaya Amador, se incorporaron a la Legión del Caribe, un destacamento revolucionario que, teniendo sede en Costa Rica, luchaba contra los regímenes dictatoriales de Centroamérica: Jorge Ubico, en Guatemala; Maximiliano Hérnandez Martínez, en El 
Salvador; y Carías, en Honduras. Una de esas conspiraciones tuvo lugar el 21 de noviembre de 1943 cuando varios patriotas trataron de producir una sublevación castrense contra la tiranía, pero, infelizmente, un desertor de última hora denunció el plan y todos los revolucionarios fueron detenidos. El jefe del movimiento fue Emilio Gómez Rovelo, quien buscó refugio en México. ${ }^{29}$

Mientras tanto, en Nicaragua gobernaba otro dictador, quizá uno de los más sangrientos de todas las brutales dictaduras del siglo xx latinoamericano, la de Anastasio Somoza García. En Venezuela se impuso la de Marcos Pérez Jiménez de 1948 a 1958 tras derrocar un grupo de militares al gobierno de Rómulo Gallegos, que duró únicamente nueve meses. ${ }^{30}$ En Cuba en marzo de 1952 Fulgencio Batista da un golpe de Estado. ${ }^{31}$ En Colombia Gustavo Rojas Pinilla hace lo mismo en 1957.

Pero sólo en algunos países se modificó la situación a finales de los años cuarenta cuando comenzó a cambiar algo el panorama. En Honduras termina el régimen de Tiburcio Carías Andino (1949) y en Guatemala se suceden los gobiernos de Juan José Arévalo (1944-1951) y Jacobo Arbenz Guzmán (1951-1954), gobiernos que seguían en gran medida el modelo de la Revolución Mexicana con un programa reformista. La Ley de la Reforma Agraria afectaba a los terratenientes y a las empresas extranjeras como la United Fruit Company, y junto con ello, la compra de armas por parte del gobierno a la Unión Soviética agravó la crisis que degeneró en un golpe de Estado, encabezado éste por el general Castillo Armas y ampliamente respaldado por la Casa Blanca. Así, miles de

${ }^{29}$ Longino Becerra, Evolución histórica de Honduras, Tegucigalpa, Baktún, 1983, p. 158.

${ }^{30}$ Cfr. Felícitas López Portillo, Historia documental de Venezuela, tomo II, México, UNAM, 2003; Germán Carrera Damas, Una nación llamada Venezuela, Caracas, Monte Ávila Editores, 1991, pp. 147-191 y Guillermo Morón, Los presidentes de Venezuela 1811-2003, Caracas, Planeta, 2003.

${ }^{31}$ Fidel Castro, Hoy somos un pueblo entero, conquistando el porvenir, México, Siglo XXI Editores, 1978; Sergio Guerra Vilaboy y Alejo Maldonado Gallardo, Historia de la Revolución Cubana. Síntesis y comentario, Quito, Ediciones La Tierra, 2005; Severio Tuttino, Breve historia de la Revolución cubana, México, Era, 1979 y Marcos Winocur, Historia social de la Revolución cubana (1952-1959), México, unAM, 1989. 
refugiados guatemaltecos llegaron a México y con ellos el mismo Arbenz Guzmán que murió en ese país en 1971.32

También para mediados y finales de los cincuenta sucede un hecho determinante para la vida política latinoamericana que tuvo que ver con las repercusiones de la Revolución Mexicana en la región. Es el refugio de Fidel Castro en México, momento y espacio que aprovecharon los revolucionarios cubanos para organizar el Movimiento 26 de Julio y emprender los preparativos de la expedición del Granma. ${ }^{33}$ Asimismo en ese periodo fue incorporado a las filas de los expedicionarios el que sería desde entonces hasta nuestros días el más destacado guerrillero latinoamericano: Ernesto Guevara de la Serna. ${ }^{34}$ El 25 de noviembre de 1956 salió del puerto de Tuxpan el yate Granma dirigido por Fidel Castro y otros combatientes del futuro ejército rebelde del Movimiento 26 de Julio. Más de dos años después, el $1^{\circ}$ de enero de 1959 entrarían triunfantes a La Habana las columnas del Ejército Rebelde. Con este hecho histórico la Revolución cubana se vuelve el nuevo paradigma para América Latina. Sin embargo, la Revolución Mexicana, desde la lógica de mantener una política exterior independiente, seguía teniendo vigencia con todos sus aciertos, errores y fracasos.

Tras la invasión mercenaria a Playa Girón y tras la expulsión de Cuba de la Organización de Estados Americanos, la política exterior mexicana seguía manifestando su carácter independiente y declarativamente revolucionario. Cabe apuntar que Canadá y México fueron los únicos países del continente que mantuvieron sus relaciones diplomáticas con la isla desde el triunfo revolucionario hasta nuestros días.

Con la administración del presidente Adolfo López Mateos (19581964), se procuró acrecentar las relaciones de toda índole con varios países del mundo, aunque también hubo conflictos con el gobierno de

${ }^{32}$ Cfr. Jorge Toriello, Tras la cortina del banano, México, FCE, 1976.

${ }^{33}$ Adalberto Santana, "La travesía del Granma", Cuadernos Americanos, Nueva Época, núm. 25, año V, vol. 1, México, enero-febrero, 1991, pp. 87-102.

${ }^{34}$ Adalberto Santana, "Ernesto Che Guevara en México", Cuadernos Americanos, Nueva Época, núm. 69, año XII, vol. 3, México, mayo-junio, 1998, pp. 179-199. 
Guatemala y rupturas diplomáticas con Honduras a raíz del golpe de Estado del 3 de octubre de 1963, dirigido por el coronel Oswaldo López Arellano, quien también en 1956 había encabezado otro golpe semejante. ${ }^{35}$ Más tarde, durante el gobierno del presidente Gustavo Díaz Ordaz (1964-1970), se desarrolló una política menos activa en el plano internacional. En lo interno se caracterizó por la represión a la oposición emergente de los sectores medios, tal como ocurrió en 1968. Éste fue un momento en que el régimen llamado "revolucionario" entró en una fuerte crisis política e ideológica. Su parteaguas es la represión al movimiento estudiantil. Tras la toma militar de diversas universidades, escuelas e institutos y con la matanza de estudiantes en la Plaza de Tlatelolco, el 2 de octubre, el régimen "revolucionario" comenzó a generar su más fuerte crisis de credibilidad interna, la cual se prolongó por más de 34 años.

A inicios de los años setenta, cuando gobierna Luis Echeverría Álvarez (1970-1976), se planeó recomponer la credibilidad interna e insertar al gobierno mexicano en el plano internacional. Así surgió un nuevo régimen neopopulista en donde el Estado se fortaleció económicamente y llevó a cabo una política exterior más independiente. Se vuelve discursivamente más revolucionario con Luis Echeverría Álvarez. Este gobierno se identificó con una política tercermundista; se ofrece asilo a los refugiados políticos chilenos tras el derrocamiento militar del gobierno socialista de Salvador Allende en 1973, así como a argentinos, uruguayos, bolivianos y peruanos, entre otros, debido a los diversos golpes de Estado o a las represiones políticas ocurridos en esa década. Asimismo se reconoce a Belice como nación soberana ${ }^{36}$ y se brinda reconocimiento diplomático a la Organización para la Liberación de Palestina (OLP). De igual manera se condena al régimen de Francisco Franco ante la ONU a mediados del decenio de los setenta.

${ }^{35}$ Cfr. Adalberto Santana, Honduras-México, una relación horizontal, Tegucigalpa, Ediciones Subirana, 1999, pp. 83-84.

${ }^{36}$ Cfr. Francesca Gargallo y Adalberto Santana [coords.], Belice: sus fronteras y destino, México, CCYDEL-UNAM, 1992. 
En esos mismos momentos crece en Centroamérica el conflicto regional, el gobierno mexicano, encabezado por José López Portillo (19761982), toma partido por las fuerzas opositoras. En 1979 rompe, junto con Venezuela y Costa Rica, sus relaciones con la dictadura de Somoza y reconoce al Frente Sandinista de Liberación Nacional (FSLN) como una fuerza política beligerante. Las diferencias en la política exterior de varios gobiernos latinoamericanos donde imperaban dictaduras y el de México se pueden explicar por el fuerte alineamiento que los primeros tenían con Washington, en tanto que, para el segundo, la política exterior en la etapa de la posguerra era frente a Estados Unidos un signo de independencia. Esa administración se desarrollaba sin contratiempos, hasta que hace crisis el auge petrolero, elemento fundamental para la burocracia política mexicana, ya que ello le imprimió un gran margen de acción internacional, en particular en su papel en el conflicto centroamericano. Sin lugar a duda a ello se sumaba la propia voluntad política y protagónica del propio presidente mexicano.

México, con una presencia más activa en el escenario internacional, había reivindicado el derecho de la Revolución Sandinista en Nicaragua a ser respetado y se había también comprometido por el respeto de la autodeterminación en El Salvador, cuestión que entró evidentemente en choque con la nueva dimensión política que cobraba el gobierno republicano estadounidense. Esto se combinó con la nacionalización de la banca que llevó a radicalizar a determinados sectores empresariales para actuar plenamente en la oposición neoconservadora. Es decir, esto dio pie para que un amplio grupo de actores empresariales se sumaran al Partido Acción Nacional (PAN).

En 1982, el $1^{\circ}$ de diciembre asumía la presidencia de México Miguel de la Madrid Hurtado (1982-1988). En aquellos momentos el gobierno mexicano se orientaba por una política exterior multilateral activa. Así, participó junto con los gobiernos de Panamá, Colombia y Venezuela en una serie de acciones que se plasmaron a través del llamado Grupo Contadora. Los logros de este grupo pueden definirse por haber contribuido a la pacificación de la región. Su acción más vigorosa fue el evitar que se expandiera territorialmente la guerra y disminuyera su intensidad. En el fondo de la 
política exterior mexicana estaba como objetivo de su estrategia económica y política hacia Centroamérica, el reafirmar la independencia y soberanía de México dentro del contexto regional e internacional y, por lo tanto, tenía prioridad el contrarrestar las influencias foráneas. En otras palabras, se buscaba que la diplomacia mexicana lograra en su calidad de país en desarrollo, "madurar y conservar su independencia política, económica y militar para permanecer, crecer y perdurar como nación soberana". ${ }^{37}$

Los logros en la pacificación de América Central se plasmaron en la última década del siglo Xx. El mejor ejemplo fueron los Acuerdos de Paz para El Salvador, firmados en el Castillo de Chapultepec de la ciudad de México en enero de 1992. ${ }^{38}$ Ya para entonces gobernaba el país, Carlos Salinas de Gortari. Para algunas lecturas la Revolución Mexicana había concluido. El PRI sufría fuertes convulsiones en 1987, principalmente la generada por Cuauhtémoc Cárdenas y Porfirio Muñoz Ledo que encabezan la Corriente Democrática. Otros sectores empresariales se desligaban del gobierno priísta y se orientaban hacia una militancia abierta por el neoconservador Partido Acción Nacional.

Las políticas neoliberales comenzaron a acentuarse a mediados de los años ochenta. Se puede señalar que los niveles de pobreza, violencia política y exclusión no cesaron en México y América Latina. Por el contrario, éstos se incrementaron en todo el conjunto de la región en el último decenio del siglo XX, entre otras razones por la aplicación de las llamadas políticas del ajuste estructural. ${ }^{39}$

${ }^{37}$ Contraalmirante Mario Santos Caamal, "México frente a Centroamérica. Un concepto estratégico nacional en acción”, en Raúl Benítez Manaut y Ricardo Córdova Macías [comps.], México en Centroamérica: expediente de documentos fundamentales 19791986, México, CEIICH-UnAM, 1989, p. 137.

${ }^{38}$ Cfr. "Discursos pronunciados el 16 de enero de 1992 en la Ciudad de México, durante la firma de los acuerdos de paz de El Salvador", Cuadernos Americanos, núm. 32, México, marzo-abril, 1992, pp. 125-143.

${ }^{39}$ La organización de las Naciones Unidas para la Agricultura y la Alimentación (FAO) en octubre de 1995, reconocía que: "El 46 por ciento de la población de América Latina es pobre, concentrándose en esa proporción el problema de acceso a la alimentación y persistente inseguridad alimentaria”, Novedades, México, 19 de octubre, 1995, p. A9. 
En México este fue el resultado a que se llegó por completo abandono de los viejos postulados nacionalistas del Partido Revolucionario Institucional (PRI) que produjo la salida de su ala izquierda, encabezada por Cuauhtémoc Cárdenas en las postrimerías del mandato de Miguel de la Madrid (1982-1988) y la creación del Partido de la Revolución Democrática (PRD), esto último a raíz de la cuestionada elección presidencial de $1988 .{ }^{40}$

Para 1989, en pleno proceso de consolidación, el modelo de ajuste neoliberal mexicano presentaba la necesidad de liberalizar las relaciones políticas y comerciales y con ello se enterraba una de las últimas herencias de la Revolución Mexicana, así como su influencia en otros países latinoamericanos.

Las repercusiones comenzaron con el gobierno de Ernesto Zedillo (1994-2000) y en el de Vicente Fox. En el primero, por ejemplo, en su alineamiento con la política de la Casa Blanca y con la doctrina neoliberal que se comenzó a hacer más evidente con la puesta en práctica del Tratado de Libre Comercio de América del Norte (TLCAN) y sobre todo con el estallido de la rebelión indígena en Chiapas en enero de $1994 .^{41}$

La respuesta más inesperada provino del levantamiento guerrillero del hasta entonces desconocido Ejército Zapatista de Liberación Nacional (EZLN) - cuyo vocero era el subcomandante Marcos - en la selva lacandona de Chiapas, el $1^{\circ}$ de enero de 1994 . Tras la toma por los rebeldes indígenas chiapanecos de las poblaciones de San Cristóbal de las Casas, Altamirano, Las Margaritas, Ocosingo, Oxchuc, Huixtan y Chanal, se emitió la "Declaración de la Selva Lacandona", un sentido llamado a la lucha por la democracia, la libertad y la justicia para todos los mexicanos. [...] En estos hechos, como también se revelaría después en otros países latinoamericanos, particularmente en Ecuador y Bolivia, se puso de relieve el papel protagónico adquirido por sujetos sociales aparentemente adormecidos, como el movimiento indígena,

40 Sergio Guerra Vilaboy, Breve Historia de América Latina, La Habana, Editorial de Ciencias Sociales, 2006, p. 301.

${ }^{41}$ Cfr. Chiapas, la palabra de los armados de verdad y fuego. Entrevistas, cartas y comunicados del EZLN (hasta el 4 de marzo de 1994), México, Ediciones del Serbal, 1994, y J. Jesús María Serna Moreno, México un pueblo testimonio. Los indios y la nación de nuestra América, México, CCYDEL-unam, 2003. 
con sus cuestionamientos implícitos o explícitos a la tradicional soberanía territorial de los estados y sus aspiraciones de autodeterminación para las etnias autóctonas, tras más de cinco siglos de dominación ininterrumpida. [...] Todos estos acontecimientos allanaron el camino para que en el 2000 se produjera, por primera vez desde la Revolución Mexicana de principios de siglo, la derrota del partido de gobierno (el PRI) con el ascenso a la presidencia de Vicente Fox, del derechista Partido Acción Nacional. ${ }^{42}$

Así, Zedillo y Fox terminaron por enterrar definitivamente a la Revolución Mexicana con su política privatizadora en el plano nacional y latinoamericano. Pero también establecieron el retorno de la banca estatizada al sector privado, así como otra diversidad de activos del Estado mexicano. Esta política siguió profundizándose en la administración de Vicente Fox, particularmente con respecto a la Revolución cubana y a la Revolución bolivariana de Venezuela, con las que se llegó al más profundo enfriamiento de las relaciones diplomáticas y a una casi total subordinación a las políticas de la Casa Blanca. En otras palabras, desde finales de la década de los años ochenta los gobiernos que se consideraban herederos de la Revolución Mexicana, rompieron con ella como si fuera un viejo fardo que les impedía reconocerse discursivamente como neoliberales y neoconservadores.

En los primero cinco años del siglo XXI, con la ampliación de la democracia formal y representativa a través de un sistema de partidos, la legitimidad ya no se justificaba en un discurso revolucionario. Por el contrario, a mitad de la primera década de dicho siglo, en las palabras oficiales se procura ya no venerar a los héroes tradicionales con una clara imagen antiintervencionista, como los Niños Héroes, defensores de la nación frente a la intervención estadounidense de 1847, a Benito Juárez, a Francisco Villa o a Emiliano Zapata. Para ese momento casi únicamente se ponderaban básicamente las virtudes del libre mercado. Los gobiernos de Zedillo y Fox fortalecieron la política privatizadora de beneficiar a las empresas transnacionales. En concreto, su proyecto era

${ }^{42}$ Guerra Vilaboy, op. cit., p. 301. 
fortalecer el neoconservadurismo, minar la potencia del Estado, llevarlo a su mínima expresión y, por lo tanto, aniquilar con ello diversas expresiones culturales y artísticas nacionales y populares que surgieron como los mejores productos de la Revolución Mexicana. Incluso por razones políticas referidas a las elecciones del 2 de julio de 2006, el presidente Vicente Fox decidió cancelar el tradicional desfile del 20 de noviembre, que fuera presidido desde el balcón central del Palacio Nacional durante varios gobiernos priístas e incluso los cinco primeros años del mismo mandatario. La razón, entre otras, era evitar una impugnación popular a 10 días del fín de su mandato, sobre todo cuando se impuso por un pequeño margen del 0.5\% el candidato del Partido Acción Nacional, Felipe Calderón Hinojosa contra su principal adversario Andrés Manuel López Obrador. Máxime cuando se reconoció el amplio apoyo oficial a la candidatura de Calderón y el hostigamiento político contra el candidato de la Coalición por el Bien de Todos. Pero también en el fondo lo que se estaba haciendo por parte del gobierno neoconservador era concluir la fase de participación del Estado y de amplios sectores sociales en las fiestas populares que en México de manera oficial celebraban el inicio de la Revolución Mexicana.

\section{REFLEXIÓN FINAL}

El auge de la Revolución Mexicana, finalmente lo podemos reconocer como el periodo que va de 1910 a 1940. Etapa que concluye cuando comienzan a formarse organizadamente las fuerzas del partido neoconservador que hoy está en el poder en México y que impulsa esencialmente, en nuestra fase actual, los cambios para borrar los últimos vestigios revolucionarios como es la pretensión de la privatización de la industria petrolera y eléctrica.

Sin lugar a dudas, el tema de la proyección continental de la Revolución Mexicana seguirá presente todavía por mucho tiempo. Por ser un tema político y por ende polémico, como es el análisis de un fenómeno revolucionario, se puede estar de acuerdo total o parcialmente con deter- 
minadas visiones de un hecho político de tal trascendencia. Incluso desde específicas lecturas se podrá estar en total desacuerdo con su significado y trascendencia. Sin embargo, la importancia político-cultural de la Revolución Mexicana para nuestra historia latinoamericana sigue presente y es una referencia fundamental para comprender las perspectivas y el desarrollo de las revoluciones de nuestro nuevo siglo XXI latinoamericano. Esto es, para leer desde el análisis comparativo y crítico los errores y aciertos que puedan desarrollar las nuevas revoluciones políticas latinoamericanas en la construcción del socialismo del siglo XXI que, sin duda, está por escribirse en los nuevos episodios de la lucha política latinoamericana. Tareas impostergables, que para el análisis de la teoría revolucionaria, la Revolución Mexicana sigue siendo una referencia obligatoria de nuestro tiempo en los comienzos del tercer milenio. 
